\title{
Substantiation of the theoretical and methodological approach to planning the work of rolling stock in the conditions of Eastern Siberia
}

\author{
Sergey Vakhrushev ${ }^{1}$ and Liudmila Trofimova ${ }^{1^{*}}$ \\ ${ }^{1}$ Siberian State Automobile and Highway University (SibADI), Mira str., 5, Omsk \\ 644080, Russia
}

\begin{abstract}
The substantiation of the theoretical and methodological approach was carried out as a result of identifying probabilistic indicators that affect the planned performance of the rolling stock and determine the properties of the types of activities for the maintenance and repair of rolling stock, the transportation of goods by transport units that provide the main production of oil and gas in Eastern Siberia. The work of special equipment is taken into account. The specificity of road, transport, climatic, seasonal conditions is taken into account when planning the production and labor intensity of each unit of rolling stock, presented as a set of parts, and assemblies.
\end{abstract}

\section{Introduction}

The implementation of large-scale transport projects outlined as part of the implementation of the energy-resource option for the development of the transport system, indicated in the "Transport Strategy of the Russian Federation for the Period up to 2030", is aimed at ensuring the production and development of mineral deposits in new production areas (oil in Eastern Siberia, gas on the Arctic shelf and etc.). New transport projects involve both the construction of oil and gas pipelines, as well as the design and construction of new roads for the operation of rolling stock, ensuring the extraction and transportation of minerals. An example is the Eastern Siberia - Pacific Ocean oil pipeline (ESPO). To ensure the uninterrupted operation of ESPO, it is necessary to plan the operation of the rolling stock that provides the main production in Eastern Siberia (southwest of the Republic of Sakha (Yakutia)). The aim of the work is to substantiate a theoretical and methodological approach to planning the work of rolling stock in the conditions of Eastern Siberia.

\footnotetext{
* Corresponding author: trofimova_ls@mail.ru
} 


\section{Material and methods}

The development of Eastern Siberia has caused the need to study issues related to the operation of rolling stock, which provides the main production for the extraction of minerals in operating conditions that have their own characteristics.

In the studies of G.V.Kramarenko, N.S.Kuznetsov, it was found that the change in the parameters of the technical condition of the rolling stock is influenced by the operating modes of units and parts, depending on the operating conditions under which it is being used. These include: road conditions, traffic conditions, transport conditions, climatic, seasonal conditions.

The influence of operating conditions on the work of the rolling stock was studied in detail at the scientific school under the leadership of LG Reznik at the Department of Operation and Repair of Cars of the Tyumen Industrial Institute. As a result of the research, causal relationships were established between the potential properties of the structure and operational factors, which included: load and speed modes of units, temperature conditions of the unit, properties of the internal environment, potential properties of the structure, technical condition of the unit (formula 1) [1].

$$
U=f\left(q, V_{T}, t M, T c\right)
$$

where - q - load mode of the unit, $\mathrm{kg}, \mathrm{V}_{\mathrm{T}}$ - speed mode $\mathrm{km} / \mathrm{h}$, tM - unit temperature, ${ }^{\circ} \mathrm{C}$, Tc - technical condition, $\%$.

N.S.Zakharov [2] established the dependence of changes in the condition of tires, fuel consumption, changes in the quality of engine oil, the formation of the realizable labor intensity of current repairs from changes in ambient temperature, road conditions, the intensity of operation of rolling stock, changing over time throughout the year. The influence of operating conditions on the material and technical supply system for maintenance and repair of rolling stock, the influence of rolling stock operating time on costs for spare parts in Western Siberia has been proved.

In work [3], it was found that the peculiarities of the operation of cars in the Far North are unfavorable meteorological conditions (extremely low temperatures, maximum wind speeds), relocation of cars from one object to another, working with separation from the main bases in remote areas. the state of tires, fuel consumption, changes in the state of engine oil, the formation of the realizable labor intensity of current repairs from changes in ambient temperature, road conditions, the intensity of operation of rolling stock, changing over time throughout the year. The influence of operating conditions on the material and technical supply system for maintenance and repair of rolling stock has been proved.

S.P.Ozornin [4] presents the factors that have their own evaluation criteria and determine the level of severity of the operating conditions of the rolling stock, which are ranked by experts: 1 - climatic conditions; 2 - the condition of the road surface; 3 - quality of technical service; 4 - use of carrying capacity.

N.S. Zakharov, A.N. Makarov [5] proved that the system "Cars - operating conditions" is a dynamic, intensively changing system, in which it is difficult to determine uniform standards for all.

The dependences of the probability of refusals on the intervals of maintenance were studied by foreign authors. HR Alla, R Hall, DB Apel [6] E. Angeles, M Kumral [7], using the example of the transportation of goods by mining dump trucks in open pit mining in Canada, determined the optimal maintenance intervals in terms of reliability in such a way as to detect potential failures that lead to significant downtime costs. Planning is carried throught taking into account the mileage from the beginning of operation.

The results of the study showed that in difficult climatic conditions, the labor intensity of performing maintenance and repairs is a random variable [8]. 
We agree with the research performed by V.M. Belyaev N.A. Filippova V.N. Bogumil [9] that for planning work in the Far North, which includes a major part of the regions of Eastern Siberia, the timing of navigation plays significant importance.

The planning of cargo transportation in the Far North was performed by V.M. Vlasov, N.A. Filippov [10], who developed two groups of factors necessary for the organization of northern delivery, namely external factors, which include difficult natural and climatic conditions, underdeveloped transport infrastructure, social conditions. Internal factors include transportation time, technical condition of vehicles during transportation, insufficient qualifications of specialists from organizations providing northern delivery.

At present, the practice of planning the labor intensity of work on maintenance and repair of rolling stock of transport units is carried out in accordance with the requirements of the manufacturer, set forth in the Vehicle Operation Manual, taking into account the correction factors, for climatic and road conditions proposed in the Guide. Reducing the likelihood of car breakdown and derailing is achieved by planning maintenance during the period when cars are at the premises of the enterprise, which is preceded by timely car diagnostics.

Studies of the practice of rolling stock in oil and gas production enterprises have shown that the planned labor intensity of work differs from the actual one by up to $30 \%$.

Annual production planning is carried out based on a fixed number of rolling stock of a certain standard size, which has carried out transportation along a specific length of a trip with cargo. Due to the fact that trips are carried out in different road conditions and, as a rule, these conditions are unique for each transportation, the planned number of rolling stock differs from the one actually involved in the work. This leads to additional costs. In the practice of transport enterprises in the oil and gas industry, the specialists of the operation department and technical services jointly solve the problem of scheduling the work of the rolling stock to ensure the activities of the main production.

In this regard, in order to achieve this goal, the following tasks are solved:

- determination of indicators that affect the properties of the types of activities for transportation, maintenance and repair of rolling stock in the conditions of Eastern Siberia;

- a classification of types of activities has been developed in relation to the operation of rolling stock in the conditions of Eastern Siberia.

\section{Theory}

The theoretical significance of this work consist of the developed classification of types of activities, taking into account the indicators that affect maintenance and repairs on the performance and transportation of goods by transport units that provide the main production for oil and gas production in Eastern Siberia. The developed classification will make it possible to describe the properties of activities, taking into account the influence of climatic, road transport and seasonal conditions on each unit of rolling stock, presented as a set of parts, components and assemblies, the impact on which determines the total labor intensity. The classification considers the modes of operation of special equipment (Fig. 1).

The work of the rolling stock is carried out in the structural division of the oil and gas production enterprise, which provides the main production associated with the production of oil and gas, the main purpose of which is to minimize the cost of transporting goods. 


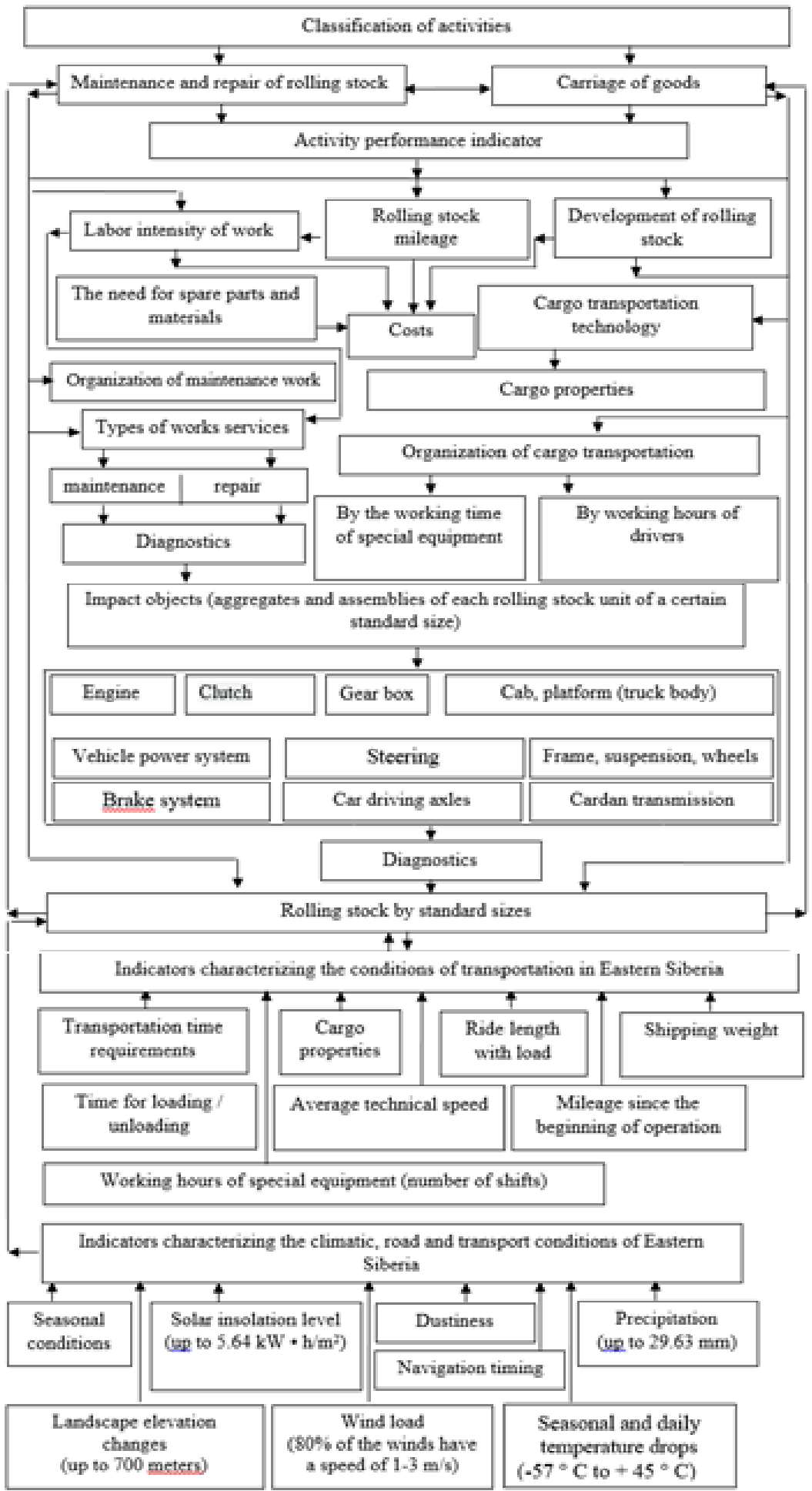

Fig. 1. Classification of activities to provide main production with rolling stock 
The mileage of rolling stock carries out the relationship between production and labor intensity and determines the amount of transportation costs. In the presented classification, the production of rolling stock depends on the organization of the transportation of goods, not only according to the working and resting hours of drivers, but also according to the operating time of special equipment (Fig. 1).

A study of the practice of rolling stock in the conditions of Eastern Siberia showed that truck tractors work in conjunction with truck cranes, dump trucks with tractor loaders [11].

The classification takes into account that when determining the production capacity of a rolling stock fleet, the capacity of special equipment is a fundamental variable [12].

According to the research of NS Zakharov, AN Makarova [5], the presented scheme allows to consider the system "Car - operating conditions" taking into account the specifics of the rolling stock operation in the conditions of Eastern Siberia.

The operating conditions of rolling stock in Eastern Siberia in relation to the newly developed territories differ from the conditions of other territories for which research was done out earlier. In addition, the transportation of goods is carried out over long distances by rolling stock with various types of bodies and semitrailers with a carrying capacity of up to 40 tons. The climate plays significant role, it imposes its own characteristics on the planning of the work of the rolling stock when transporting the goods of the enterprise. Seasonal temperature changes are very large, from $-57^{\circ} \mathrm{C}$ to $+45^{\circ} \mathrm{C}$, landscape elevation changes up to 700 meters, solar insolation level up to $5.64 \mathrm{~kW} \cdot \mathrm{h} / \mathrm{m} 2$, small amount of precipitation - up to $29.63 \mathrm{~mm}$, and small wind load, $80 \%$ of the winds have a speed of $1-3$ $\mathrm{m} / \mathrm{s}$, another $15 \%-4-5 \mathrm{~m} / \mathrm{s}$ [13] (Fig.1)

During the winter, for adhesion of car tires to the road surface, is treated with sand and chipped stone, which, at the same time, when cars are moving, negatively affect almost all structural elements of the rolling stock. In the summer, dust from the sand and gravel mixture on the roads rises to a height of 4-5 meters and remains in the air for a long time, prematurely disabling air filters, unprotected rubbing structural elements.

The scientific foundations of current planning, taken into consideration the relationship between the transportation of goods and the implementation of maintenance and repair, were presented in [14]. To determine the planned indicators and their relationship, it was proposed to use the length of the ride with the load and the mass of the shipment.

In the presented classification, it is taken into account that the average technical speed affects the potential properties of the structure of each unit of rolling stock, and in the road conditions of Eastern Siberia it affects the shift production of rolling stock.

When describing the properties of activities, it should be considered that with an increase in their service life rolling stock, performance has a negative trend [15].

As indicators that form the properties of activities, a probabilistic indicator is taken into account - the time for loading and unloading, which according to foreign scientists and practitioners, is a required condition for optimizing the rolling stock operation plan in all periods of time [16]. The use of probabilistic indicators makes it possible to calculate both the lower and upper bounds of the optimal objective function [17], to minimize the internal resources for carrying out transportation [18].

\section{Conclusions}

In the article, as a result of a study of the work of scientists and practitioners, the practice of rolling stock in transport units that provide the main production for oil and gas production in Eastern Siberia, indicators are determined that affect the properties of activities for maintenance and repair of rolling stock, cargo transportation. 
It has been established that seasonal conditions, the level of solar activity, seasonal and daily temperature drops, precipitation, landscape elevation changes, wind loads, typical for the conditions of Eastern Siberia, affect the units and assemblies of each rolling stock unit.

The conditions of transportation are characterized by probabilistic indicators, the average length of a ride with a load, an average technical speed, downtime during loading and unloading, and the mass of a shipment. The developed classification will allow taking into account the properties of an interconnected system when changing the operating modes of special equipment.

The results of the presented studies will be used to develop an innovative methodology for solving the problem of planning the operation of rolling stock of freight road transport in the conditions of Eastern Siberia using a computer program. The methodology will use a mathematical model and the dependence of planned indicators on probabilistic values that characterize the process of performing maintenance and repairs, transportation of goods, and operating modes of special equipment.

\section{References}

1. L. G. Reznik, A. I. Yagovkin Causal relationship of the potential properties of the structure and operational factors that determine the wear rate of transsmission units in winter conditions, Automobile transport: scientific works, issue № 49, Tyumen Industrial Institute: Tyumen, pp. 152 -156, (1975)

2. L. G. Reznik, D. A. Zakharov Complex indicator of the fitness of cars, The importance of technical regulations in solving the problems of creating and operating cars in the conditions of Siberia and the Far North, Materials of the extraordinary conferenceseminar of the Association of Automotive Engineers, Omsk; Surgut: Polygraphic Center of KAN, pp. 29-30, (2005)

3. N. S. Zakharov, S. A. Tenkovskaya, A.V. Vlasov Improving the methodology for forming the need for spare parts for cars when servicing oil and gas production facilities, Transport, Transport facilities, Ecology, № 2, pp. 32-40, (2019)

4. S. P. Ozornin, I. A. Tarasov Methods and results of evaluating the efficiency of operation of cargo vehicles in cold climate conditions, Bulletin of the Irkutsk State Technical University, V. 22, № 3, pp. 234-243, (2018)

5. N. S. Zakharov, A. N. Makarova Operational correction of vehicle maintenance standards, Transport and transport-technological systems, Materials of international relations. Sci. - tech. conf. Tyumen, Tyumen Industrial University, pp. 115-117, (2015)

6 HR Alla , R. Hall, DB Apel Performance evaluation of near real-time condition monitoring in haul trucks, International journal of mining science and technology, $\mathbf{T}$. 30, V. 6 pp. 909-915, (2020)

7. E. Angeles, M. Kumral, Optimal Inspection and Preventive Maintenance Scheduling of Mining Equipment, Ournal of failure analysis and prevention, T. 20, № 4, pp. 14081416, (2020)

8. A. Tumanggor, Reliability value analysis of dump truck 108 unit (case study: South Kalimantan coal mining company), International Conference on Manufacturing, Optimization, Industrial and Material Engineering, V. 2044, №16, pp. 30-35, (2018)

9. N. A. Filippova, V. N. Bogumil, V. M. Belyaev On forecasting the timing of navigation based on Markov chains, The world of transport, V. 17, № 2, pp. 16-25, (2019)

10. N. A. Filippova, V. M. Vlasov Methodology for improving the efficiency and reliability of the transport and technological multimodal system of the North of Russia, Scientific Bulletin of MSTU GA, V. 22, № 06, pp. 55-65, (2019) 
11. S. A. Vakhrushev Features of the practice of rolling stock operation during cargo transportation in the conditions of the Far North, Construction equipment and technologies, № 3 (23) , pp. 4-11, (2020)

12. F. Kristjanpoller, P. Viveros, E. Zio, R. Pascual, O. Aranda Equivalent availability index for the performance measurement of haul truck fleets, Eksploatacja $\mathrm{i}$ niezawodnosc-maintenance and reliability, T. 22, V. 4, pp. 583-591, (2020)

13. A. N. Gorokhov, A. N. Fedorov Modern trends of climate change in Yakutia. Geography and natural resources, №. 2, pp. 111-119, (2018)

14. L. S. Trofimova, N. G. Pevnev The structure of the methodology of current planning of the work of a cargo transport enterprise, Bulletin of SibADI, № 6(58), pp. 71-78, (2017)

15. V. D. Shepelev, Z. V. Almetova, P. I. Ageev, E. V. Shepeleva Modeling of the efficiency of the use of truck motor transport depending on the period of its operation, Bulletin of SUSU, V. 12, № 2, pp. 179-184, (2018)

16. JY Liu, JL Mao, JJ Liao, HQ Hu, Y Guo, AY Zhou SCLPD: Smart Cargo Loading Plan Decision Framework, 36th International Conference on Data Engineering (ICDE 2020), pp. 1758-1761, (2020)

17. M. Gaudioso, M. F. Monaco, M. A. Sammarra, Lagrangian heuristics for the truck scheduling problem in multi-door, multi-product Cross-Docking with constant processing, Omega (United Kingdom), pp. 120-128, (2021)

18. F. Zheng, Y. Pang, Y. Xu, Heuristics for cross-docking scheduling of truck arrivals, truck departures and shop-floor operations, Journal of Combinatorial Optimization, pp. 365-372. (2021) 